\title{
Habilidades Sociais de desempregados de uma região de indústria coureiro-calçadista
}

\section{Social skills of unemployed workers from a region of leather and footwear industries}

\section{Kamêni I ung Rolim*}

Faculdades Integradas de Taquara - FACCAT, Taquara, RS, Brasil

\section{Karla Rafaela Haack**}

Faculdades Integradas de Taquara - FACCAT, Taquara, RS, Brasil

\section{Camila Roberta Lahm-Vieira***}

Faculdades Integradas de Taquara - FACCAT, Taquara, RS, Brasil

\author{
Alessandra Rodrigues J acoby**** \\ Faculdades Integradas de Taquara - FACCAT, Taquara, RS, Brasil

\section{Jefferson Silva Krug**} \\ Faculdades Integradas de Taquara - FACCAT, Taquara, RS, Brasil
}

\begin{abstract}
RESUMO
Em alguns contextos, observa-se a tendência a explicar os níveis de desemprego tão somente a partir das características pessoais dos trabalhadores, referenciando a ideia socialmente difundida de que pessoas em situação de desemprego possuem déficits em habilidades sociais. 0 presente trabalho objetivou discutir a questão da empregabilidade mediante a caracterização do perfil de trabalhadores em situação de desemprego e da mensuração dos níveis de Habilidades Sociais (HS) apresentados pelos mesmos. Participaram do estudo 100 pessoas em situação de desemprego. Foram aplicados individualmente um questionário sóciobiodemográfico e uma adaptação do Inventário de Habilidades Sociais (IHS). Nas análises descritivas e de diferença entre médias verificou-se que os participantes não apresentaram déficits nas habilidades mensuradas quando comparados à população geral. O estudo sugere que os níveis de HS não são suficientes para explicar o fenômeno em questão, propondo reflexões a partir do conceito de empregabilidade.
\end{abstract}

Palavras-chave: Desemprego, Empregabilidade, Habilidades sociais.

\begin{abstract}
Within some contexts, there is a trend of explaining unemployment levels exclusively from the workers' personal characteristics by referring the socially divulged idea that unemployed people have deficits of social skills. The current paper aimed at discussing the employment ability issue by outlining the features of the unemployed workers' profile and by measuring their levels of Social Skills (SS). A total of one hundred unemployed people participated of the study. A social, bio- and demographic questionnaire as well as an adapted Inventory of Social Skills (ISS) were applied to each
\end{abstract}


subject individually. In both the descriptive analysis and the analysis of difference between averages, one found out that the participants did not show deficits in the measured skills when compared to the population in general. The study suggests that the SS levels are not enough to explain the approached phenomenon and proposes reflections starting from the concept of employment skills.

Keywords: Unemployment, Employment ability, Social skills.

O tema do desemprego tem, cada vez mais, sido alvo de estudos em diversas esferas da ciência, abarcando reflexões sobre fatores que estão implicados no estabelecimento e na manutenção desta situação. Entre esses fatores, encontramos a questão da falta de preparo técnico dos trabalhadores, que durante muito tempo vigorou como sendo um dos principais argumentos explicativos do elevado número de desempregados (MINARELLI, 1995). Contudo, pesquisas (FELISBERTO, 2001; GUIMARÃES; GOULART, 2002) têm sugerido que o preparo técnico não é mais suficiente para garantir o emprego atualmente, inclusive considerando que até mesmo a formação universitária não oferece as mesmas vantagens para a inserção e crescimento no mercado de trabalho como ocorria em anos anteriores. Essa realidade é constatada também junto às agências de intermediação do Sistema Nacional de Empregos (SINE) no Vale do Paranhana - Rio Grande do Sul. Nessas observou-se que existem muitas vagas de emprego que não são preenchidas, apesar de haver candidatos capacitados tecnicamente para tal.

Contudo, em certos contextos, em especial na mídia, parece prevalecer o sofisma de que os desempregados estão nesta situação por não possuírem o preparo técnico e pessoal adequado. Intrincada a essas reflexões e considerações, a temática da empregabilidade ocupa um lugar de destaque no que concerne a estudos e debates sobre o assunto. Esse construto é descrito por vários autores, estando presente nos diferentes olhares lançados sobre o tema vieses que privilegiam as características individuais do trabalhador, o contexto de trabalho e a realidade social.

O termo empregabilidade foi criado por José Augusto Minarelli no final dos anos noventa (MINARELLI, 1995), e faz menção à capacidade do profissional em adequar-se à necessidade e à dinâmica dos novos mercados de trabalho. Está constituída sobre seis pilares, que, segundo o autor, indicam os itens a serem levados em consideração para os indivíduos terem boa empregabilidade, ou seja, serem empregáveis aos olhos do contratante: a) adequação da profissão à vocação (seria indispensável harmonizar a função com a capacidade e paixão pelo que se faz); b) competências (preparo técnico, capacidade de liderar pessoas, habilidade política, habilidade de comunicação oral e escrita em pelo menos dois idiomas, habilidade em marketing, habilidade de vendas, capacidade de utilização de recursos tecnológicos); c) idoneidade (além de ética, conduta, 
correção e respeito); d) saúde física e mental (equilíbrio do corpo e da mente, evitando desgaste exagerado e vícios como fumo, álcool e drogas, além de manter autoestima e capacidade de realizar projetos); e) reserva financeira e fontes alternativas de aquisição de renda (guardar todos os meses uma quantia para caso de desemprego, além de pensar em um próprio negócio e fontes alternativas de renda); f) relacionamentos (ter uma boa networking, cuidando com carinho dos relacionamentos, retornado ligações e mantendo contato com estas pessoas).

Complementando as considerações de Minarelli (1995), outros autores (RUEDA; MARTINS; CAMPOS, 2004; LIBERAL; PUPO, 2008) têm estabelecido entendimentos acerca da empregabilidade, pautados basicamente sobre aspectos de cunho individual e de interação com o meio, perpassando o mercado de trabalho e elementos do cenário atual. Para Rueda, Martins e Campos (2004), a empregabilidade deve redirecionar as relações capital/trabalho na era da informação. Diante desse novo contexto, a capacidade de o indivíduo mobilizar múltiplos saberes, conhecimentos e habilidades bem como o preparo para batalhar pela sobrevivência no mundo organizacional são os fatores mais desejados pelos contratantes (LIBERAL; PUPO, 2008). Para esses autores, imaginar que a empregabilidade esteja somente associada a variações na escolaridade e na experiência dos indivíduos seria um exercício reducionista, uma vez que outros fatores também são importantes, destacando-se as qualidades pessoais e interrelacionais.

Sob essa ótica, faz-se importante considerar os estudos sobre habilidades sociais (HS). Essas podem ser compreendidas como um conjunto de comportamentos apresentados por uma pessoa que facilitam sua interação com os demais, em determinado contexto (SARRIERA; CAMARA; BERLIM, 2000), e dessa forma estariam relacionadas a diferentes funções e padrões de comportamento dos indivíduos. Del Prette e Del Prette (2008) apontam que:

Funcionalmente, as habilidades sociais se definem pela relação entre as instâncias de respostas observáveis em episódios de interação social e os antecedentes (demandas ou estímulos discriminativos) e conseqüentes (observados ou inferidos como prováveis a curto e/ou médio prazo) associados a essas respostas. Além da função, também a forma da resposta é importante para caracterizá-la como habilidade social. A diversidade de combinações entre as características formais e funcionais de determinadas respostas sociais, caracteriza um amplo conjunto de classes de comportamento que podem ser classificadas como: habilidades sociais de comunicação, de assertividade, empáticas, de solução de problemas interpessoais, dentre outras. Cada uma dessas classes é geralmente composta por 
subclasses, como por exemplo, perguntar, responder, concordar, discordar, instruir, questionar.

Ademais, as HS possuem especificidade situacional-cultural (DEL PRETTE; DEL PRETTE, 1999), o que significa que os indivíduos podem ser socialmente habilidosos em um contexto e não em outro e, além disso, um mesmo desempenho social pode ser considerado competente em um contexto e não em outro.

Del Prette e Del Prette (2006) apontam ainda que as HS também são tema de interesse da área organizacional, uma vez que indivíduos com bom relacionamento interpessoal são também mais produtivos no âmbito do trabalho. Pessoas socialmente habilidosas contribuem para a melhoria do clima organizacional, bem como para a qualidade das relações. Isso porque a construção do repertório de comportamentos sociais ocorre em contextos naturais nas interações do indivíduo com outras pessoas e sem um treinamento formal. Porém, falhas comumente ocorrem nesses processos, o que pode ocasionar em déficits em HS (MURTA, 2005).

Apesar de as HS estarem diretamente implicadas nas tarefas previstas para a eficácia da empregabilidade, o estabelecimento da relação direta entre empregabilidade e HS pode, no entanto, gerar erros interpretativos importantes quanto ao fenômeno do desemprego. O modelo sistêmico da empregabilidade propõe a existência de três níveis de influência e caráter macrossistêmico a esse fenômeno: o contexto sóciopolítico-econômico, as características do contexto local/regional e o mercado de trabalho. Esses níveis relacionam-se a esferas que se constituem em determinantes para a criação de diferentes nuances que, intrincadas e interagindo com e sobre a empregabilidade, a um nível macrossistêmico, abarcam o perfil do trabalhador. Ainda que ressalte a importante influência de aspectos macrossistêmicos sobre a empregabilidade, Câmara (1999) afirma que muitos são os fatores constituintes do perfil do trabalhador implicados nesse tema, tais como: nível de escolaridade e formação, nível sócio-econômico e cultural, atributos psico-cognitivos, história laboral, habilidades sociais e para o trabalho, recursos do meio, aspectos físicos e étnicos.

Portanto, a presente pesquisa surge a partir dessa reflexão acerca da relação entre HS e empregabilidade encontrada na literatura, bem como da demanda fomentada pelas agências de intermediação de emprego do SINE da Região do Vale do Paranhana, no Estado do Rio Grande do Sul. Essa região tem sua economia alicerçada sobremaneira no setor de serviços e de indústrias, sendo a maioria de indústrias coureiro-calçadistas (IBGE, 2008). Nessa realidade observa-se, além do desemprego, a presença de alta rotatividade nas vagas dentro das empresas. Essa problemática na região tende a ser explicada com os mesmos argumentos apresentados pelo modelo de 
empregabilidade que atribui a situação de desemprego ao fracasso do trabalhador, creditando essa condição apenas a fatores individuais.

A partir dessa realidade, buscando caracterizar em termos de habilidades sociais os indivíduos em situação de desemprego que foram atendidos nas agências do SINE, levantou-se o questionamento sobre a presença ou não de diferenças entre o repertório de HS de indivíduos desempregados e a população geral. Entende-se que ao responder essa questão pode-se refletir acerca da hipótese de que indivíduos desempregados apresentam menores níveis de habilidade social que pessoas da população geral.

\section{Método}

Participaram deste estudo exploratório de caráter quantitativo 100 pessoas em situação de desemprego que possuíam mais de 18 anos de idade e que procuraram os serviços de agências do SINE em dois municípios da região do Vale do Paranhana-RS. Foram utilizados dois instrumentos: um questionário sóciobiodemográfico e uma adaptação, em razão do nível educacional dos participantes, do Inventário de Habilidades Sociais-IHS-Del-Prette (DEL PRETTE; DEL PRETTE, 2005). A adaptação desse inventário foi necessária, pois o IHS-Del-Prette foi validado para utilização em adultos e jovens com formação mínima de ensino médio. Como a maioria dos desempregados possuía ensino fundamental ou médio incompletos, teve-se a preocupação de adaptar a linguagem para facilitar a compreensão dos participantes, buscando não modificar o sentido ou a ordem das questões. Esse procedimento foi feito através do uso de juízes que sugeriram palavras mais comumente utilizadas pela população a ser estudada para, posteriormente, ser observada a compreensão dos sujeitos para cada questão formulada.

O IHS é composto por trinta e oito itens, que contemplam cinco fatores: 1) Enfrentamento e autoafirmação com risco: reúne itens que avaliam o conceito de assertividade; 2) Autoafirmação na expressão de sentimento positivo: reúne itens que retratam demandas interpessoais por afeto positivo e afirmação de autoestima; 3) Conversação e desenvoltura social: traz itens que retratam situações sociais neutras, de aproximação com risco mínimo de reação indesejável; 4) Autoexposição a desconhecidos e situações novas: inclui situações que envolvem a abordagem de pessoas desconhecidas; e 5) Autocontrole da agressividade: reúne itens que supõem estímulos aversivos do interlocutor, demandando controle da raiva e da agressividade. O Inventário traz também sete questões que não representam nenhum fator.

$\mathrm{Na}$ seleção dos participantes do estudo, foi utilizado o critério de escolha por conveniência (COZBY, 2008), a partir do convite feito aos desempregados enquanto aguardavam ao atendimento na agência de intermediação de empregos. Os sujeitos foram convidados a se dirigir 
a uma sala privada onde o convite para participação da pesquisa foi feito mediante leitura, compreensão e assinatura do Termo de Consentimento Livre e Esclarecido (TCLE). Todos os cuidados éticos, em se tratando de pesquisa com seres humanos, foram tomados visando resguardar os direitos dos participantes, de acordo com as normas da Resolução no 196/96 sobre Pesquisas Envolvendo Seres Humanos, do Conselho Nacional de Saúde (2006). Os entrevistados foram esclarecidos que suas respostas ao instrumento não exerceriam influência sobre os motivos que os levaram até a agência do SINE. Após a assinatura do TCLE, os sujeitos responderam individualmente aos instrumentos da pesquisa.

Os dados coletados foram tabulados e analisados com o auxílio do programa estatístico SPSS (Statistics Program for Social Sciences). Realizaram-se análises descritivas e de diferenças entre as médias dos níveis de HS de desempregados e as médias dos níveis de HS da população geral contidas no manual do IHS. Foi utilizado o teste $t$ de Student para avaliar as diferenças entre as médias.

\section{Análise e discussão dos resultados}

Inicialmente, apresenta-se a Tabela 1 com dados relativos à caracterização sociobiodemográfica da amostra estudada: 
Tabela 1

Caracterizaçäo sociobiodemográfica

\begin{tabular}{|c|c|c|}
\hline \multirow{4}{*}{ Idade } & De 18 a 25 anos & $38 \%$ \\
\hline & De 26 a 35 anos & $33 \%$ \\
\hline & De 36 a 45 anos & $18 \%$ \\
\hline & Mais de 45 anos & $11 \%$ \\
\hline \multirow{2}{*}{ Sexo } & Feminino & $59 \%$ \\
\hline & Masculino & $41 \%$ \\
\hline \multirow{3}{*}{ Estado Civil } & Solteiro & $49 \%$ \\
\hline & Casado/Morando Junto & $45 \%$ \\
\hline & Separado/Divorciado/Viúvo & $6 \%$ \\
\hline \multirow{3}{*}{ Escolaridade } & Ens. Fundamental Completo & $45 \%$ \\
\hline & Ens. Médio Inconqleto/Conqleto & $45 \%$ \\
\hline & Ens. Superior Inoompleto/Completo & $10 \%$ \\
\hline \multirow{2}{*}{ Está estudando? } & Sim & $22 \%$ \\
\hline & Hão & $78 \%$ \\
\hline \multirow{2}{*}{ Tem fillos? } & Sim & $62 \%$ \\
\hline & Hão & $38 \%$ \\
\hline \multirow{4}{*}{ Renda Familiar } & Áté 2 salários múnimos & $48 \%$ \\
\hline & De 2 a 4 salários múumos & $36 \%$ \\
\hline & Mais de 4 salários múnimos & $14 \%$ \\
\hline & Hão respondeu & $2 \%$ \\
\hline \multirow{2}{*}{$\begin{array}{c}\text { Já fez uso do Seguro } \\
\text { Desemprego? }\end{array}$} & Sim & $74 \%$ \\
\hline & Wão & $26 \%$ \\
\hline \multirow{4}{*}{$\begin{array}{c}\text { Se usou o Seguro } \\
\text { Desemprego, quantas } \\
\text { vezes of fez? }\end{array}$} & 1 vez & $30 \%$ \\
\hline & 2 vezes ou 3 vezes & $35 \%$ \\
\hline & 4 ou mais vezes & $9 \%$ \\
\hline & Wão uson & $26 \%$ \\
\hline
\end{tabular}

Quanto à caracterização da população que buscou os serviços do SINE, observou-se que $59 \%$ eram mulheres, $38 \%$ possuíam de 18 a 25 anos e $33 \%$ de 26 a 35 anos. Além disso, $49 \%$ eram solteiros e $62 \%$ possuíam ao menos um filho. Com relação à renda familiar, $48 \%$ recebiam até 2 salários mínimos. No que concerne à escolaridade, 45\% possuíam Ensino Fundamental completo, 45\% tinham Ensino Médio incompleto/completo e $10 \%$ tinham Ensino Superior incompleto/completo.

Dada a juventude da amostra, constata-se a alta rotatividade dos trabalhadores. Isso porque, com relação ao uso do benefício social Seguro Desemprego, 30\% da amostra utilizou o benefício uma vez, e $44 \%$ utilizou duas vezes ou mais. Quanto a esse ponto, estudo (SILVESTRIN; TRICHES, 2008) indica que o índice de rotatividade elevado constitui-se como uma estratégia adotada por muitas empresas do setor coureiro calçadista para reduzir os níveis de salário 
reais. Por outro lado, a rotatividade pode se tornar um problema para muitas empresas, pois muitos cargos exigem treinamento dos profissionais, e assim a empresa acaba gerando custos para reposição de pessoal. Vários fatores influenciam na permanência ou saída do funcionário da empresa, entre eles a satisfação no trabalho pode ser um dos fatores mais pesquisados com relação à rotatividade. Diversos autores consideram a insatisfação dos empregados, com relação ao cargo que desempenham, como um dos principais aspectos desse fenômeno. Assim diversas pesquisas confirmam que existe correlação negativa entre satisfação no trabalho e rotatividade (HERZBERG, 1964; VROOM, 1964; LÉVI-LEBOYER, 1994).

A tabela abaixo registra os níveis gerais de HS das participantes do sexo feminino, em comparação com a média da população geral feminina do IHS:

\section{Tabela 2}

Niveis de habilidades sociais de mulheres de sempregadas comparadas com niveis de habilidades sociais da população geral de mulheres

\begin{tabular}{|c|c|c|c|c|}
\hline \multirow[b]{2}{*}{ Fatores } & \multicolumn{2}{|c|}{ Médias } & \multirow[b]{2}{*}{$\mathrm{p}$} & \multirow[b]{2}{*}{$\mathrm{t}$} \\
\hline & $\begin{array}{c}\text { Mulheres } \\
\text { Desempregadas }\end{array}$ & $\begin{array}{c}\text { Populaçăo Geral } \\
\text { Feminitia }\end{array}$ & & \\
\hline $\mathrm{F} 1$ & 23,06 & 22,03 & 0,259 & 1,140 \\
\hline $\mathrm{F} 2$ & 19,96 & 21,68 & $0,001^{* k}$ & $-3,363$ \\
\hline F3 & 20,78 & 16,78 & $0,000^{*-k x}$ & 6,684 \\
\hline $\mathrm{F} 4$ & 9,67 & 9,10 & 0,199 & 1,300 \\
\hline F5 & 9,13 & 7,20 & $0,000^{-k-k}$ & 6,905 \\
\hline ESCORE TOTAL & 82,62 & 76,79 & $0,000^{\text {kks: }}$ & 3,938 \\
\hline
\end{tabular}

*** diferença significativa entre os grupos

Observa-se que, no que tange ao sexo feminino, houve diferença estatisticamente significativa entre os níveis apresentados nos fatores F3 (Conversação e desenvoltura social) $(p=0,000)$, F5 (Autocontrole da agressividade) $(p=0,000)$ e Escore Total das HS $(p=0,000)$. Esses dados sugerem que as mulheres desempregadas que responderam ao estudo apresentam maiores níveis de habilidade social que a média geral da população feminina com relação às HS para lidar com chacotas e critica, cumprimentar pessoas desconhecidas, encerrar ou manter uma conversação, reagir a um elogio, recusar pedidos abusivos, abordar autoridade, encerrar uma conversa ao telefone e pedir favores a colegas. 
Esse dado possibilita a problematização de estudos afirmando que altos níveis de HS são aspectos potencializadores da empregabilidade. Sendo assim, poderíamos questionar Del Prette e Del Prette (2006) quando afirmam que indivíduos com bom relacionamento interpessoal são também mais produtivos no âmbito do trabalho. Em estudo anterior, Del Prette e Del Prette (2003) salientaram a importância das HS para o rendimento profissional, devido a sua influência sobre a vida afetiva dos indivíduos. No entanto, na amostra estudada, apresentar altos níveis de HS não garantiu a manutenção de seus postos de trabalho.

Nesse aspecto, cabe contextualizar que a principal atividade laboral das pessoas dessa amostra está relacionada à indústria coureirocalçadista, principalmente em funções que envolvem trabalho mecânico pouco flexível a mudanças dentro de linhas de produção como corte de couro, costura de partes de calçados, colagem, entre outros. Caracterizado como um trabalho precariamente remunerado ( $84 \%$ ganham até 4 salários mínimos como renda familiar). As linhas de montagem absorvem, em sua maioria, trabalhadoras com menor grau de instrução e pouca experiência profissional, uma vez que nesses postos de trabalho são exigidas apenas constantes ações repetitivas e concentração extrema visando à diminuição de erros e o aumento da qualidade dos produtos. Por essas razões, as atividades são executadas individualmente, com pouca ou nenhuma interação entre funcionários. Essa pouca interatividade é estimulada pelos supervisores, uma vez que representa aumento nos riscos de acidentes de trabalho. Nesse contexto, entende-se que possuir mais habilidades de conversação e desenvoltura social (Fator 3) pode representar um risco maior à qualidade do produto dessas linhas de montagem, o que poderia compor um quadro explicativo sobre a dificuldade dessas mulheres em se manterem empregadas nesse tipo de posto de trabalho, já que as habilidades apresentadas por elas tendem a ser rejeitadas nesse ambiente laboral.

Outro resultado encontrado diz respeito ao menor nível de autoafirmação na expressão de sentimento positivo (Fator 2) $(p=0,001)$ na amostra de mulheres desempregadas em relação à população geral feminina. Sabe-se que o desemprego é gerador de sentimentos de menos valia, tristeza e depressão (SARRIERA; CÂMARA; BERLIM, 2000), dificultando o estabelecimento de uma visão positiva da realidade, atentando à integridade física e psicológica dos trabalhadores.

Por serem estimuladas à competição no mercado de trabalho, exigese das mulheres um ritmo de trabalho excessivo, acarretando na necessidade de lotação em cargos de múltiplas funções. Os cargos ocupados, por sua vez, são quase sempre designados como periféricos em termos de importância estratégica para a empresa, como, por exemplo, "auxiliares de produção". Além disso, as 
mulheres são obrigadas a desenvolverem habilidades sem qualquer treinamento, seus espaços físicos são constituídos em uma perspectiva isolada, a comunicação com os colegas torna-se proibida e por vezes são expostas a violências verbais ou físicas (BRITO, 1996). Partindo dessa consideração da literatura, pode-se hipotetizar que, provavelmente, as mulheres desempregadas da amostra apresentem maiores níveis de sintomas depressivos, interferindo na habilidade para expressar sentimentos positivos sobre si e sobre os outros ao seu redor.

Soma-se a esses aspectos as repercussões de uma prática bastante comum entre mulheres que estão desempregadas do setor coureiro calçadista: o trabalho a domicílio. Essa realidade descentraliza algumas etapas da produção calçadista através da subcontratação (SCHNEIDER, 2004), obrigando as mulheres a conciliarem seu trabalho com a rotina doméstica e familiar.

Já no que tange aos níveis de HS dos participantes do sexo masculino, em comparação com a média da população geral masculina do IHS, obteve-se os seguintes resultados:

\section{Tabela 3:}

Niweis de habilidades sociais de homens desempregados comparados com niveis de habilidades sociais da populaçăo geral de homens

\begin{tabular}{|c|c|c|c|c|}
\hline \multirow[b]{2}{*}{ Fatores } & \multicolumn{2}{|c|}{ Médias } & \multirow[b]{2}{*}{$\mathrm{p}$} & \multirow[b]{2}{*}{ t. } \\
\hline & $\begin{array}{c}\text { Homens } \\
\text { Desempregados }\end{array}$ & $\begin{array}{c}\text { População Geral } \\
\text { Masculina }\end{array}$ & & \\
\hline$\overline{F 1}$ & 24,00 & 25,59 & 0,104 & $-1,662$ \\
\hline $\mathrm{F} 2$ & 19,39 & 20,22 & 0,235 & $-1,205$ \\
\hline F3 & 20,25 & 17,31 & $0,004 * *$ & 3,069 \\
\hline F4 & 9,59 & 8,99 & 0,270 & 1,118 \\
\hline F5 & 8,75 & 8,15 & 0,203 & 1,294 \\
\hline ESCORE TOTAL & 81,99 & 80,26 & 0,487 & 0,701 \\
\hline
\end{tabular}

** diferenç a significativa entre os grupos

Verificou-se (Tabela 3) que houve diferença estatisticamente significativa $(p=0,004)$ apenas no Fator 3 que avalia os níveis de conversação e desenvoltura social. As hipóteses explicativas desse resultado, em consonância com a realidade vivenciada pela amostra, também podem dizer respeito ao fato de tais habilidades não serem compatíveis com as habilidades desejadas para os candidatos na ocupação dos postos de trabalho disponíveis na região, o que foi 
também observado no escore da amostra de mulheres desempregadas deste estudo.

Também foram analisadas diferenças entre os níveis de HS de desempregados jovens (menos de 30 anos) e desempregados maduros (mais de 30 anos). As tabelas 4 e 5 apresentam os níveis de HS, de acordo com a idade dos participantes e o sexo desses.

\section{Tabela 4}

Niveis de habilidades sociais de mulheres desempregadas con até 30 anos comparadas com niveis de habilidades sociais de mulheres desempregadas com mais de 30 anos

\begin{tabular}{|c|c|c|}
\hline \multirow[b]{2}{*}{ Fatores } & \multicolumn{2}{|c|}{$\begin{array}{c}\text { Wulheres desempregadas com menos de } 30 \\
\text { anos } X \text { Mulheres de sempregadas con mais } \\
\text { de } 30 \text { anos }\end{array}$} \\
\hline & $\mathrm{p}$ & $\mathrm{t}$ \\
\hline F1 & 0,116 & 1,597 \\
\hline $\mathrm{F}_{2}$ & 0,959 & $-0,052$ \\
\hline F3 & 0,843 & 0,199 \\
\hline F4 & 0,324 & 0,994 \\
\hline F5 & 0,520 & $-0,647$ \\
\hline ESCORE TOTAL & 0,231 & 1,210 \\
\hline
\end{tabular}

Em relação à idade dos participantes, verificou-se (Tabela 4) que não houve diferença significativa $(p>0,050)$ entre mulheres desempregadas jovens e maiores de 30 anos. 


\section{Tabela 5}

Niweis de habilidades sociais de homens de sempregados com ate 30 anos comparadas com niveis de habilidades sociais de homens desempregados com mais de 30 anos

\begin{tabular}{c|c|c}
\hline & \multicolumn{2}{|c}{$\begin{array}{c}\text { Homens desempregados com menos de 30 } \\
\text { anos X Homens desempregados com mais }\end{array}$} \\
\hline Fatores & $\mathrm{2}$ & $\mathrm{t}$ \\
\hline F1 & 0,543 & $-0,614$ \\
F2 & 0,934 & $-0,084$ \\
F3 & $0,015 * *-$ & $-2,553$ \\
F4 & 0,351 & $-0,944$ \\
F5 & 0,480 & $-0,712$ \\
ESCORE TOTAL & 0,126 & $-1,563$ \\
\hline
\end{tabular}

*** diferença signific ativa entre os grupos

No tocante aos níveis de HS de homens desempregados jovens e maiores de 30 anos (Tabela 5), houve diferença significativa no Fator 3 (Conversação e desenvoltura social) $(p=0,015)$ indicando que homens jovens possuem menor índice de habilidades nesse fator do que homens com mais de 30 anos. Ainda com relação aos homens desempregados com mais de 30 anos, embora não tenha havido diferença significativa entre os escores nos demais fatores, pode-se observar que esses possuem maiores médias no que tange aos cinco fatores e Escore Total referente ao IHS, conforme indica o t (Tabela $5)$, em comparação com homens desempregados com menos de 30 anos.

Esses resultados podem ser consequência da construção do repertório de comportamentos sociais oriundos de ambientes de convívio social (MURTA, 2005). Isso pode ser compreendido levando em consideração que a aquisição e o desenvolvimento de HS ocorrem ao longo do desenvolvimento humano, variando em função do estágio desenvolvimental e de variáveis situacionais e culturais (DEL PRETTE; DEL PRETTE, 1999). Quanto mais experiências sociais um indivíduo tiver, maiores serão as oportunidades de aquisição e desenvolvimento de habilidades. Nesse sentido, os homens com mais de 30 anos parecem ter tido oportunidades, ao longo do ciclo vital, de maior desenvolvimento de suas habilidades de conversação e desenvoltura social.

Ademais, cabe salientar que as mulheres jovens do contexto pesquisado vivenciam uma realidade social que tem, cada vez mais, 
se aberto para o trabalho feminino. Aquelas mais maduras talvez ainda apresentem médias menores de habilidade na maioria dos fatores (como pode ser visto nos valores de t da Tabela 4) em razão de um histórico mais tardio de inserção no mercado de trabalho. Quando jovens, a maioria vivenciou uma época em que a mulher dispunha de escassas alternativas de emprego e trabalho assalariado. Isso não ocorreu com a amostra de homens. Esses dados podem sugerir que as mulheres jovens vêm galgando o espaço há muito já conquistado pelos homens mais velhos no que se refere à ocupação de vagas no mercado de trabalho e o consequente desenvolvimento das HS advindas do convívio grupal possibilitado por esse ambiente. Soma-se a isso a constatação de Lavinas (2001) que aponta em sua pesquisa a existência de maior "grau de empregabilidade" entre as mulheres atualmente. Para a autora, esse diferencial de gênero se deve ao fato de que o atributo pessoal credenciado pela dimensão feminina, hoje fortemente demandado pela "nova economia", somado a vantagens objetivas (escolaridade e menor custo de contratação), permite às mulheres realizar ganhos de diferencial, sumamente importantes.

Entre os fatores que parecem influenciar de maneira significativa o desenvolvimento de HS está o nível de escolaridade (CÂMARA, 1999). Isso pode ser observado nas Tabelas 6 e 7.

\section{Tabela 6}

Niveis de habilidades sociais de mulheres desempregadas com até Vivel Fundamental comparados com niveis de habilidades sociais de mulheres desempregadas com mais do que Nivel Fundamental

\begin{tabular}{c|c|c}
\hline & \multicolumn{2}{|c}{$\begin{array}{c}\text { Wulheres Desempregadas com até Vivel } \\
\text { Fundamental Completo X Mulheres }\end{array}$} \\
& $\begin{array}{c}\text { Desempregadas com mais do que Nivel } \\
\text { Fundamental Completo }\end{array}$ \\
\hline Fatores & $\mathrm{p}$ & $\mathrm{t}$ \\
\hline F1 & $0,034^{* * *}$ & $-2,176$ \\
F2 & 0,431 & $-0,793$ \\
F3 & 0,517 & $-0,653$ \\
F4 & 0,104 & $-1,654$ \\
F5 & 0,296 & 1,055 \\
ESCORE TOTAL & $0,034 * *$ & $-2,170$ \\
\hline
\end{tabular}

*k diferença significativa entre os grupos 
Tabela 7

Niweis de habilidades sociais de homens de sempregados com até Niwel Fundamental comparados com niveis de habilidades sociais de homens desempregados com mais do que Nivel Fundamentã

\begin{tabular}{c|c|c}
\hline & $\begin{array}{r}\text { Homens Desempregadas com até Vivel } \\
\text { Fundamental Comple to X Homens } \\
\text { Desempregadas com mais do que Nivel }\end{array}$ \\
& \multicolumn{2}{|c}{ Fundamental Comple to } \\
\hline Fatores & $p$ & $t$ \\
F1 & 0,117 & $-1,605$ \\
F2 & 0,186 & $-1,346$ \\
F3 & 0,910 & 0,113 \\
F4 & 0,827 & 0,219 \\
F5 & 0,828 & $-0,218$ \\
ESCORE TOTAL & 0,359 & $-0,929$ \\
\hline
\end{tabular}

Observa-se na Tabela 6 que houve diferença significativa entre os escores médios de mulheres desempregadas com até Ensino Fundamental Completo e mulheres desempregadas com mais do que essa escolaridade no que se refere ao Fator $1(p=0,034)$ e ao Escore Geral $(p=0,034)$. Além disso, mesmo não se encontrando diferença significativa nos outros fatores, a maioria das médias de HS das mulheres com mais anos de estudo mostrou-se superior a de mulheres com baixa escolaridade, como indicam os escores de $t$.

Indo ao encontro dos dados da Tabela 6, os resultados encontrados na amostra de homens (Tabela 7) demonstram que os desempregados com escolaridade superior ao Nível Fundamental Completo apresentaram maiores níveis de HS do que homens com baixa escolaridade. Esse dado da pesquisa corrobora os achados de Bandeira et al. (2006) que salientam a presença de correlação entre níveis de HS e escolaridade de forma diretamente proporcional.

\section{Considerações Finais}

Sendo as HS fatores integrantes do perfil profissional do indivíduo, concebe-se que as mesmas intrincam-se na entrada e manutenção no mercado de trabalho. Este estudo exploratório demonstrou que pessoas em situação de desemprego apresentam níveis de HS semelhantes ou até mesmo superiores à média da população geral. 
Isso representa dizer que a dificuldade na inserção em vagas no mercado de trabalho e a manutenção nos postos de trabalho não se restringem à ausência de habilidades, mas talvez, entre outros aspectos sócio-econômicos, à incompatibilidade de características desta população com as vagas ofertadas nestas empresas. Outra razão possível para explicar o resultado alcançado pode residir no fato de que essas pessoas não tenham suas habilidades estimuladas, aproveitadas e valorizadas no ambiente de trabalho descrito acima, o que invariavelmente pode vir a ocasionar maiores níveis de desmotivação, falta de envolvimento no trabalho e sofrimento psíquico.

No contexto analisado neste estudo, a fragmentação da produção calçadista ocorre com diversas operações, cada qual executada por um trabalhador submetido ao ritmo da esteira fordista. Por questões econômicas, as empresas contam com o trabalho domiciliar de mulheres e crianças, produzindo a baixo custo elementos do produto final, que as máquinas não podem fazer (RIGOTTO, 2007).

Todo esse panorama, sob a perspectiva da Qualidade Total, no intuito de que cada trabalhador introjete a incumbência de controlar seu próprio trabalho, configuraria um sistema diabólico de dominação autoadministrado, que angustia os/as trabalhadores/as (RIGOTTO, 2007). Isso remete a pensar na possibilidade do trabalho comprometer as habilidades humanas, ou melhor, faz considerar o quanto o contexto de trabalho pode vir a se tornar condicionante do desenvolvimento das potencialidades individuais e coletivas dos indivíduos e, assim, acometer a saúde dos trabalhadores, já que os sujeitos buscam no trabalho espaços para a realização de suas necessidades e desejos. Nesse foco de análise, a psicodinâmica do trabalho oferece subsídios que remetem à imparcialidade do trabalho na saúde mental dos trabalhadores, que pode impulsionar a inteligência criativa, o crescimento pessoal, a motivação e a felicidade, ou ofertar condições geradoras de submissão, alienação e sofrimento (DEJ OURS, 1990).

Consideramos que tais resultados refletem ainda que, para uma compreensão mais elaborada sobre as dificuldades de entrada e manutenção no mercado de trabalho, há de se reconsiderar a temática empregabilidade, no sentido de modificação de uma visão que culpabiliza o indivíduo para uma abordagem que contemple um ponto de vista sistêmico, no qual se deve considerar como fatores de risco para o desemprego variáveis contextuais, econômicas e sociais. A situação de desemprego aumenta a vulnerabilidade dos indivíduos, e, atribuir a este sujeito o fracasso na entrada do mercado de trabalho é fomentar mazelas e desigualdades. Além disso, percebe-se a necessidade de considerar a complexidade de fatores psicossociais, econômicos e políticos envolvidos na problemática. Para Schneider (2004) compreender a constituição do mercado de trabalho da 
indústria coureiro-calçadista local requer uma análise do próprio processo de transformação social pelo qual passou a região. Frente aos desafios econômicos na contemporaneidade, a busca pela empregabilidade supera o desejo de encontrar um trabalho prazeroso e fornecedor de formação e, dessa forma, o trabalhador tem se submetido a atividades repetitivas, arriscadas, insalubres, desprovidas de sentido moral e ético. Assim, o trabalhador acaba por realizar tarefas que não promovem ou potencializam habilidades intelectuais e sociais.

No contexto pesquisado, torna-se premente a realização de discussões acerca desses fatores envolvidos no mercado de trabalho local. É necessário vislumbrar que a economia das cidades alvo do presente estudo está prioritariamente focada na indústria coureirocalçadista que, imersa na realidade da globalização e dependente das exportações, torna-se vulnerável às nuances de uma economia capitalista e competitiva. Dessa forma, criam-se situações que fomentam práticas danosas, tais como demissões e recontratações em massa (SILVESTRIN; TRICHES, 2008), não valorização da mãode-obra qualificada, com remunerações aviltantes e critérios escusos para a contratação. Nesse contexto, ser habilidoso socialmente nem sempre é valorizado, pois o funcionário geralmente não permanece empregado durante muito tempo, não havendo condições para se desenvolver no ambiente de trabalho. Assim, sua habilidade de relacionamento é subaproveitada em relação a outras habilidades motoras ou cognitivas como atenção, memória e raciocínio mecânico, fundamentais para a execução de funções operacionais absorvidas nas linhas de montagem destas empresas.

Dessa forma, os dados analisados podem sugerir diferentes leituras sobre a concepção de empregabilidade. Contudo, o que se torna mais evidente é que há a necessidade de maiores elucidações sobre as problemáticas envolvidas na definição deste construto. Acredita-se que os dados coletados possam fomentar a discussão e compreensão da realidade estudada. Considerando que os participantes da amostra pesquisada possuíam níveis de habilidade semelhantes à média da população geral ou acima dela, preparo técnico e experiência profissional prévia, os dados podem sugerir que os mesmos dispõem de potencial para desenvolvimento pessoal e profissional. Todavia, fica evidente que existem dificuldades que são impeditivas de crescimento profissional para esta população e que não dizem respeito a seu despreparo técnico ou déficits em HS, podendo estar mais relacionadas a exigências macro-econômicas e modelos de gestão que não valorizam as habilidades encontradas na amostra de desempregados.

Considerando as possibilidades de atuação sobre tal problemática, poderiam ser de grande valia ações voltadas à prevenção primária, buscando potencializar novas formas de gestão e inclusão social da 
massa de trabalhadores desempregados da região através do melhor aproveitamento das habilidades apresentadas pelos indivíduos, levando em conta, além do contexto, o sexo e a idade dos participantes. Portanto, a pesquisa sugere que muito mais relevante do que práticas voltadas aos indivíduos seriam intervenções junto aos empregadores e às agências de intermediação, no sentido de fomentar novas práticas de gestão e inovações nos processos produtivos, de maneira a ampliar as possibilidades de exercício laborativo para os trabalhadores desempregados.

Assim, é possível questionar a tendência cada vez mais premente de alocar o perfil do trabalhador ao cerne da questão da empregabilidade. A consequência disso é culpar o desempregado pela sua situação. Deve-se considerar todos os outros contextos em nível de macrossistemas envolvidos para não reforçar o imperativo de que os motivos do desemprego estão somente em déficits de habilidades do trabalhador, e não nos aspectos tecnológicos adotados pelas empresas, modelos produtivos e interferências econômicas que acabam por compor as características do mercado de trabalho da região.

Assim, verifica-se que muitos são os desafios impostos pelos contextos atuais que, envoltos em processos de globalização da economia e de políticas que primam pelo acúmulo de capital, impigem ao trabalhador a demanda cada vez mais inatingível de adaptação de seu perfil a um mercado de trabalho cada vez mais volátil. Cria-se então uma situação no mínimo perigosa, pois ao responsabilizar tão somente o indivíduo, cobrando-lhe habilidades sem o fornecimento de meios para tal, acaba-se por fomentar a desigualdade e o consequente aumento nos níveis de sofrimento psíquico desses indivíduos e de seu entorno. Daí a necessidade de estimular o desenvolvimento de uma perspectiva de empregabilidade que leve em conta a complexidade da problemática do emprego e do desemprego nos diferentes contextos de nossa sociedade.

\section{Referências Bibliográficas}

BANDEIRA, M.; ROCHA, S. S.; FREITAS, L. C.; DEL PRETTE, Z. A. P.; DEL PRETTE, A. Competência acadêmica de crianças do ensino fundamental: características sociodemográficas e relação com habilidades sociais. Interação, Curitiba, v. 10, n. 1, p. 53-62, jan./jun. 2006.

BRITO, J. Trabalho e Saúde nas Indústrias de Processos Químicos: a Experiência das Trabalhadoras. Tese (Doutorado) Escola Nacional de Saúde Pública, Fundação Oswaldo Cruz, Rio de J aneiro, 1996.

CÂMARA, S. G. Perfil de empregabilidade do jovem portoalegrense: critérios de seleção nas áreas da indústria, 
comércio e serviços. 1999. Dissertação (Mestrado) - Faculdade de Psicologia, Pontifícia Universidade Católica do Rio Grande do Sul. Porto Alegre, RS.

CONSELHO NACIONAL DE SAÚDE. Resolução no 196. Diretrizes e Normas Regulamentadoras de Pesquisa. Brasil, 2006. Disponível em: <www.conselho.saude.gov.br>. Acesso em: 02 Abr. 2009.

COZBY, P. Métodos de pesquisa em ciências do comportamento. São Paulo: Atlas, 2008.

DEJOURS, C. A loucura do trabalho: estudo da psicopatologia do trabalho. São Paulo: Cortez, 1990.

DEL PRETTE, A.; DEL PRETTE, Z. A. P. No contexto da travessia para o ambiente de trabalho: treinamento de habilidades sociais com universitários. Estudos de Psicologia, Natal, v.8, n.3, set./dez., 2003.

DEL PRETTE, Z. A. P; DEL PRETTE, A. Psicologia das habilidades sociais: Terapia e educação. Petrópolis, RJ : Vozes, 1999.

Inventario de Habilidades Sociais (I HS-Del-Prette): Manual de Aplicação, Apuração e Interpretação. 3. ed. São Paulo: Casa do Psicólogo, 2005.

Relações interpessoais e habilidades sociais no âmbito do Trabalho e das Organizações. São Carlos, SP, 2006. Disponível em: <http://www.rihs. ufscar.br>. Acesso em: 12 dez. 2009.

. Um sistema de categorias de habilidades sociais educativas.

Paídéía. Ribeirão Preto, SP, v. 18, n. 41, dez. 2008. Disponível em: $<$ http://www.scielo.br/scielo.php?script=sci_Arttext\&pid=S0103863X $2008000300008 \&$ Ing $=$ pt\&nrm=iso $>$. Acesso em: 17 nov. 2009.

FELISBERTO, R. F. T. Tenho um diploma universitário, mas não tenho emprego: histórias de vida de pessoas que vivem a experiência do desemprego. 2001. Dissertação (Mestrado em Psicologia) - Universidade Federal de Santa Catarina. Santa Catarina. GUIMARÃES, R. F.; GOULART, I. B. Flechados em pleno vôo: estudo sobre impactos psicossociais e identitários que a dificuldade de inserção profissional imprime em jovens recém-graduados no ensino superior. In: XXXII Reunião Anual de Psicologia. Anais. Ribeirão Preto: SBP, 2002.

HERZBERG, F. The motivation to work. 2ed. New York: John Wiley \& Sons, 1964.

INSTITUTO BRASILEIRO DE GEOGRAFIA E ESTATÍSTICAS - IBGE. IBGE CIDADES@. Disponível em: <http://www.ibge.gov.br/cidadesat/topwindow.htm?1>. Acesso em: 15 mai. 2010.

LAVINAS, L. Empregabilidade no Brasil: Inflexões de Gênero e diferenciais Femininos. Rio de Janeiro: IPEA, 2001. Disponível em: <http://www. progetto100citta.it/documenti/fórum2/donne/sez2/EMP REGABI LI DADE\% 20NO\% 20BRASI L\% 20I NFLEX\% D5ES\% 20DE\% 20G\% 
CANERO\% 20E\% 20DIFERENCI AI S\% 20FEMININOS.pdf>. Acesso em: 25 nov. 2009.

LÉVI-LEBOYER, C. A crise das motivações. São Paulo: Atlas, 1994. LIBERAL, M. M. C.; PUPO, M. B. Fatores de empregabilidade para profissionais acima dos 40 anos de idade. Revista UNI FI EO, v. 1, n. $1,2008$.

MINARELLI, J. A. Empregabilidade: O caminho das pedras. São Paulo: Editora Gente, 1995.

MURTA, S. G. Aplicações do treinamento em habilidades sociais: análise da produção nacional. Psicologia: Reflexão \& Crítica, v. 8, p. 283-291, 2005.

RIGOTTO, R. M. Caiu na rede, é peixe: a industrialização tardia e suas implicações sobre o trabalho, o ambiente e a saúde no Estado do Ceará, Brasil. Cadernos de Saúde Pública, Rio de Janeiro, 2007.

RUEDA, F. J. M,; MARTINS, L. J.; CAMPOS, K. C. de L. Empregabilidade: o que os alunos universitários entendem sobre isto?

Psicologia: Teoria e Prática, v. 2, n. 6, p. 63-73, 2004. Disponível em: $\quad<h t t p: / / s c i e l o . b v s-p s i . o r g . b r / p d f / p t p / v 6 n 2 / v 6 n 2 a 06 . p d f>$. Acesso em: $20 \mathrm{Jul} 2009$.

SARRIERA, J. C; CAMARA, S. G; BERLIM, C. S. Elaboração, desenvolvimento e avaliação de um Programa de Inserção Ocupacional para Jovens Desempregados. Psicologia, Reflexão \& Critíca, Porto Alegre, v. 13, n. 1, 2000. Disponível em: <http://www.scielo.br/scielo.php?script=sci_arttext\&

pid=S0102-79722000000100019\&Ing=en\&nrm=iso>. Acesso em: 04 dez. 2008.

SCHNEIDER, S. O mercado de trabalho da indústria coureirocalçadista do Rio Grande do Sul: formação histórica e desenvolvimento. In: ACHYLES B; PASSOS, M.C. (Orgs.). Indústria de calçados no Rio Grande do Sul. São Leopoldo: Ed. Unisinos, 2004, p. 25-49.

SILVESTRIN, L.E.; TRICHES, D. A análise do setor calçadista brasileiro e os reflexos das importações chinesas no período de 1994 a 2004.

Revista Econômica, Rio de Janeiro, v. 10, n. 1, p. 145-170, 2008.

Disponível

em:

<http://www.uff.br/revistaeconomica/v10n1/luisiane.pdf>. Acesso em: 05 jan. 2010.

SISTEMA NACIONAL DE EMPREGO. Relatório Anual 2008 SINESistema Nacional de Empregos. Disponível em: <http://www.mte.gov.br/sine/relatorio_anual2008.pdf >. Acesso em: 27 jul. 2009.

VROOM, V. H. Work and motivation. New York: John Wiley, 1964. 


\section{Endereço para correspondência}

Kamêni I ung Rolim

Av. Oscar Martins Rangel, 4500, RS115, CEP 95600-000, Taquara, RS, Brasil

Endereço eletrônico: kameni13@yahoo.com.br

Karla Rafaela Haack

Av. Oscar Martins Rangel, 4500, RS115, CEP 95600-000, Taquara, RS, Brasil

Endereço eletrônico: kaah03@gmail.com

Camila Roberta Lahm-Vieira

Av. Oscar Martins Rangel, 4500, RS115, CEP 95600-000, Taquara, RS, Brasil

Endereço eletrônico: camilalahm@yahoo.com.br

Alessandra Rodrigues Jacoby

Av. Oscar Martins Rangel, 4500, RS115, CEP 95600-000, Taquara, RS, Brasil

Endereço eletrônico: ale@faccat.br

J efferson Silva Krug

Av. Oscar Martins Rangel, 4500, RS115, CEP 95600-000, Taquara, RS, Brasil

Endereço eletrônico: jeffsilkrug@yahoo.com.br

Recebido em: 29/06/2010

Reformulado em: 30/08/2010

Aceito para publicação em: 31/08/2010

Acompanhamento do processo editorial: Adriana Benevides Soares

\section{Notas}

* Membro do Grupo de Pesquisa Avaliação Psicológica: instrumentos e contextos (APIC/FACCAT); Discente de Psicologia das Faculdades Integradas de Taquara FACCAT

**Psicóloga pelas Faculdades Integradas de Taquara - FACCAT; Membro do Grupo de Pesquisa Avaliação Psicológica: instrumentos e contextos (APIC/FACCAT); Mestranda em Psicologia Clínica na Universidade do Vale do Sinos - UNISINOS.

*** Psicóloga pelas Faculdades Integradas de Taquara - FACCAT; Membro do Grupo de Pesquisa Avaliação Psicológica: instrumentos e contextos (APIC/FACCAT); Assistente do Curso de Psicologia das Faculdades Integradas de Taquara - FACCAT. *** Psicóloga pela UNISINOS; Especialista Em Recursos Humanos pela Faculdades Integradas de Taquara - FACCAT; Membro do Grupo de Pesquisa Avaliação Psicológica: instrumentos e contextos (APIC/FACCAT); Mestranda em Psicologia Clínica na Universidade do Vale do Sinos - UNISINOS.

*****Psicólogo pela PUC-RS; Mestre em Psicologia Clínica pela PUC-RS; Coordenador do Curso de Psicologia das Faculdades Integradas de Taquara FACCAT; Coordenador do Grupo de Pesquisa Avaliação Psicológica: instrumentos e contextos (APIC/FACCAT); Doutorando em Psicologia na Universidade Federal do Rio Grande do Sul - UFRGS. 